\title{
ASPECTOS BIOLÓGICOS E CAPACIDADE PREDATÓRIA DE Ceraeochrysa cubana (Hagen, 1861) (Neuroptera: Chrysopidae) ALIMENTADA COM Aphis gossypii Glover, 1877 (Hemiptera: Aphididae) EM DIFERENTES TEMPERATURAS
}

\author{
Biological aspects and predatory capacity of Ceraeochrysa cubana (Hagen, 1861) \\ (Neuroptera: Chrysopidae) fed on Aphis gossypii Glover, 1877 (Hemiptera: Aphididae) \\ under different temperatures
}

\author{
Eliana Alcantra ${ }^{1}$, César Freire Carvalho ${ }^{2}$, Terezinha Monteiro dos Santos ${ }^{3}$, \\ Brígida Souza $^{2}$, Lenira Viana Costa Santa-Cecília ${ }^{4}$
}

\begin{abstract}
RESUMO
Avaliou-se alguns aspectos biológicos e a capacidade predatória em três temperaturas de larvas de Ceraeochrysa cubana (Hagen) alimentadas com ninfas de terceiro e quarto ínstares de Aphis gossypii Glover. Os experimentos foram conduzidos em câmaras climáticas a $22 ; 25$ e $28 \pm 1^{\circ} \mathrm{C}, 70 \pm 10 \%$ de UR e fotofase de 12 horas. O delineamento experimental foi inteiramente casualizado com três tratamentos (temperaturas), com 40 repetições. Verificou-se redução no tempo de vida das larvas nos três ínstares, das fases de pré-pupa e pupa em função do aumento da temperatura. As maiores viabilidades foram obtidas a $22^{\circ} \mathrm{C}$. Para larvas de primeiro ínstar não houve diferença significativa no consumo médio diário nas três temperaturas. Para larvas de segundo e terceiro ínstares houve maior consumo diário de pulgões na maior temperatura. O número médio total de afídeos consumido por larvas de primeiro e segundo ínstares não diferiu em função do aumento da temperatura. Para larvas de terceiro ínstar o maior consumo total foi observado a $22^{\circ} \mathrm{C}$, e o menor a $25^{\circ} \mathrm{C}$. Na menor temperatura observou-se maior consumo médio total na fase larval.
\end{abstract}

Termos para indexação: Controle biológico, pulgão do algodoeiro, crisopídeo.

\section{ABSTRACT}

Some biological aspects and the predatory capacity at three temperatures of larvae of Ceraeochrysa cubana (Hagen) fed third and fourth instar nymphs of Aphis gossypii Glover were evaluated. The experiments were conducted in climatic chambers at $22 ; 25$ and $28 \pm 11^{\circ} \mathrm{C}, 70 \pm 10 \%$ of RH and 12 -hour photophase. The experimental design was completely randomized with three treatments (temperatures) and 40 replicates. A reduction in the median life time of the larvae in the three instars of the stages of pre-pupa and pupa was found as related with the increase of temperature. The highest survivals were obtained at $22^{\circ} \mathrm{C}$. For larvae of first instar, there were no significant differences in the daily average consumption of aphids at the three temperatures. For second and third instar larvae, there was higher consumption of aphids at the highest temperature. The total average number of aphids consumed by first and second instar larvae did not differ as related with the increase of temperature. For third instar larvae, the greatest total consumption was observed at $22^{\circ} \mathrm{C}$, and the lowest consumption at $25^{\circ} \mathrm{C}$. The lowest temperature enabled the highest total average consumption of the larval stage.

Index terms: Biological control, cotton aphid, green lacewing.

(Recebido em 22 de setembro de 2006 e aprovado em 2 de maio de 2007)

\section{INTRODUÇÃO}

Os crisopídeos são agentes promissores para o controle biológico de afídeos em casa-de-vegetação, por serem polífagos, possuírem grande habilidade para locomoção nas plantas e alta capacidade de busca, além de apresentarem ampla adaptabilidade a variações de temperatura, o que facilita o controle integrado (NÚÑEZ, 1988).
As larvas de Ceraeochrysa cubana (Hagen, 1861) (Neuroptera: Chrysopidae) são candidatas para utilização no controle biológico e no manejo integrado de insetospraga em regiões tropicais e subtropicais, podendo ser criadas massalmente e comercializadas (LÓPEZ-ARROYO et al., 1999b).

Muitas vezes o número de crisopídeos em condições naturais é inadequado para se obter um nível

\footnotetext{
Engenheira Agrônoma, Mestre - Departamento de Entomologia/DEN - Universidade Federal de Lavras/UFLA - Cx. P. 3037 - $37200-000$ - Lavras, MG lialcantra@yahoo.com.br

2Doutores, Professores - Departamento de Entomologia/DEN - Universidade Federal de Lavras/UFLA - Cx. P. 3037 - $37200-000$ - Lavras, MG cfcarvalho@ufla.br; brgsouza@ufla.br

${ }^{3}$ Doutora, Pesquisadora - Agência Paulista de Tecnologia dos Agronegócios/APTA/Pólo Regional Centro Leste - Avenida Bandeirantes, 2419 - Vila Virgínia - 14030-670 - Ribeirão Preto, SP - terezinha@aptaregional.sp.gov.br

${ }^{4}$ Doutora, Pesquisadora - Empresa de Pesquisa Agropecuária de Minas Gerais/EPAMIG - Centro Tecnológico do Sulde Minas/CTSM - Campus da UFLA Cx. P. 176 - 37200-000 - 37200-000 - Lavras, MG - scecilia@epamig.br
} 
desejado de controle de pragas, e assim torna-se necessária a criação massal em laboratório para posterior liberação de ovos e/ou larvas em casa-de-vegetação e campo (FONSECA et al., 2001). Em alguns países europeus e nos Estados Unidos esses predadores são criados massalmente e comercializados, sendo empregados no controle biológico do pulgão Aphis gossypii Glover, 1877 (Hemiptera: Aphididae) em plantas cultivadas em campo e sob cultivo protegido (KARAHROUDI \& HATAMI, 2003; STEEZL \& DEVETAK, 1999).

A biologia dos crisopídeos pode ser influenciada não só pela qualidade e quantidade do alimento, mas também pela temperatura. Essa variável trata-se de um fator abiótico de grande importância no crescimento, reprodução e comportamento dos insetos pelo fato de serem eles pecilotérmicos (TAUBER et al., 1987). Os efeitos da temperatura sobre esse grupo de insetos já foram comprovados para algumas espécies, verificando-se que a duração das diferentes fases de desenvolvimento é inversamente proporcional ao aumento da temperatura, e a velocidade do desenvolvimento diretamente proporcional a esse aumento (FONSECA et al., 2001; PESSOA et al., 2004; SILVA, 1991).

Com o presente trabalho, objetivou-se obter mais informações relacionadas à interação predador-presa, estudaram-se alguns aspectos biológicos e a capacidade predatória em três temperaturas de $C$. cubana alimentada com o pulgão A. gossypii.

\section{MATERIAL E MÉTODOS}

Para o estudo de alguns aspectos biológicos e da capacidade predatória da fase jovem de C. cubana, 40 larvas recém-eclodidas foram individualizadas em placas de Petri de $5 \mathrm{~cm}$ de diâmetro, contendo um disco foliar de $4,5 \mathrm{~cm}$ de pepino cultivar Caipira, fixados com a parte abaxial para cima, em uma lâmina de ágar:água a $1 \%$. As placas foram vedadas com tecido voil preso com elástico, e mantidas em câmaras climatizadas a $22 ; 25$ e $28 \pm 1^{\circ} \mathrm{C}$, UR de $70 \pm 10 \%$ e fotofase de 12 horas.

A alimentação das larvas consistiu de ninfas de terceiro e quarto ínstares de A. gossypii, fornecidas em número suficiente para que as larvas de $C$. cubana pudessem alimentar-se à vontade. Esse número foi determinado em um ensaio preliminar, com a finalidade de se conhecer a quantidade de afídeos consumida diariamente em cada ínstar. Para padronizar a idade das presas, foram colocados 40 fêmeas em cada unidade de criação contendo um disco foliar de pepino. Após dois dias as fêmeas foram retiradas, ficando somente ninfas de primeiro e segundo ínstares as quais, após dois dias, se encontravam no terceiro e quarto ínstares.
Após a avaliação diária do número de pulgões predados, as placas foram higienizadas retirando-se os exoesqueletos e as ninfas sobreviventes, fornecendo-se outras em igual número, durante todo o período de larva do crisopídeo.

O delineamento experimental foi o inteiramente casualizado com três tratamentos representados pelas temperaturas de $22 ; 25$ e $28^{\circ} \mathrm{C}$, com 40 repetições. Foram avaliados: duração de cada ínstar, viabilidade das fases de larva, pré-pupa, pupa e do período de larva a adulto e consumo médio diário e total de pulgões em cada ínstar e na fase larval de $C$. cubana, nas três temperaturas.

Para a construção e comparação das curvas de sobrevivência, utilizou-se o estimador Kaplan-Meier não paramétrico, considerando-se o nível de significância de $5 \%$. Para avaliar o tempo de vida dos estádios e fases de desenvolvimento de $C$. cubana utilizaram-se as estimativas pontuais, dadas pela mediana, que é o recomendado em distribuições assimétricas. Em relação à capacidade predatória, os dados foram submetidos à análise de variância e as médias comparadas pelo teste de Tukey a 5\% de significância.

\section{RESULTADOS E DISCUSSÃO}

Tempo de vida e probabilidade de sobrevivência As larvas de primeiro ínstar de $C$. cubana alimentadas com ninfas de A. gossypii, quando submetidas à temperatura de $22^{\circ} \mathrm{C}$ apresentaram um tempo mediano de vida de oito dias, ou seja, foi nesse dia que ocorreu o maior número de eventos. Os eventos estão representados nesse trabalho principalmente pela mudança de ínstar. Esses eventos começaram a ocorrer no sétimo dia e, passados dois dias, todas as larvas sobreviventes mudaram de ínstar (Tabela 1 e Figura 1). A probabilidade de sobrevivência no tempo mediano de vida de oito dias foi de $36,97 \%$, indicando que $63,03 \%$ das larvas de primeiro ínstar sofreram ecdise nesse tempo (Tabela 1).

Na temperatura de $25^{\circ} \mathrm{C}$, as larvas de C. cubana apresentaram, no primeiro ínstar, o tempo mediano de vida de seis dias, com probabilidade de sobrevivência de 46,92\%, sendo que, até esse dia, 53,08\% das larvas haviam passado para o segundo ínstar. Foi nesse dia que ocorreu a maioria dos eventos, mas, foi no quinto dia que se iniciaram, prolongando-se até o sétimo dia (Tabela 1 e Figura 1A).

A $28^{\circ} \mathrm{C}$, o tempo mediano de vida das larvas foi de cinco dias, com 30,07\% das larvas ainda no primeiro ínstar e 69,93\% já no segundo ínstar (Tabela 1). A duração máxima do período de ocorrência dos eventos das larvas de primeiro ínstar, nessa temperatura, foi de sete dias, período em que todas as larvas sobreviventes mudaram para o ínstar seguinte (Figura 1A). 
Tabela 1 - Tempo mediano de vida (T) em dias e probabilidade de sobrevivência (S) em \%, dos três ínstares de Ceraeochrysa cubana (Hagen) alimentada com Aphis gossypii Glover, em três temperaturas. UR de $70 \pm 10 \%$ e fotofase de 12 horas.

\begin{tabular}{ccccc}
\hline \multirow{2}{*}{ Ínstares } & \multicolumn{4}{c}{ Temperaturas $\left({ }^{\circ} \mathrm{C}\right)$} \\
\cline { 2 - 5 } & & 22 & 25 & 28 \\
\hline \multirow{2}{*}{$1^{\mathrm{o}}$} & $\mathrm{T}$ & 8 & 6 & 5 \\
& $\mathrm{~S}$ & 36,97 & 46,92 & 50,07 \\
\hline \multirow{2}{*}{$2^{-}$} & $\mathrm{T}$ & 8 & 5 & 23,53 \\
& $\mathrm{~S}$ & 28,26 & 48,64 & 5 \\
\hline \multirow{2}{*}{$3^{\mathrm{o}}$} & $\mathrm{T}$ & 8 & 6 & 32,0 \\
\hline
\end{tabular}

$\overline{\mathrm{T}}=$ tempo mediano em que a maioria das larvas sofreu ecdise. $\mathrm{S}=$ porcentagem de larvas que ainda não sofreram ecdise no tempo $\mathrm{T}$.
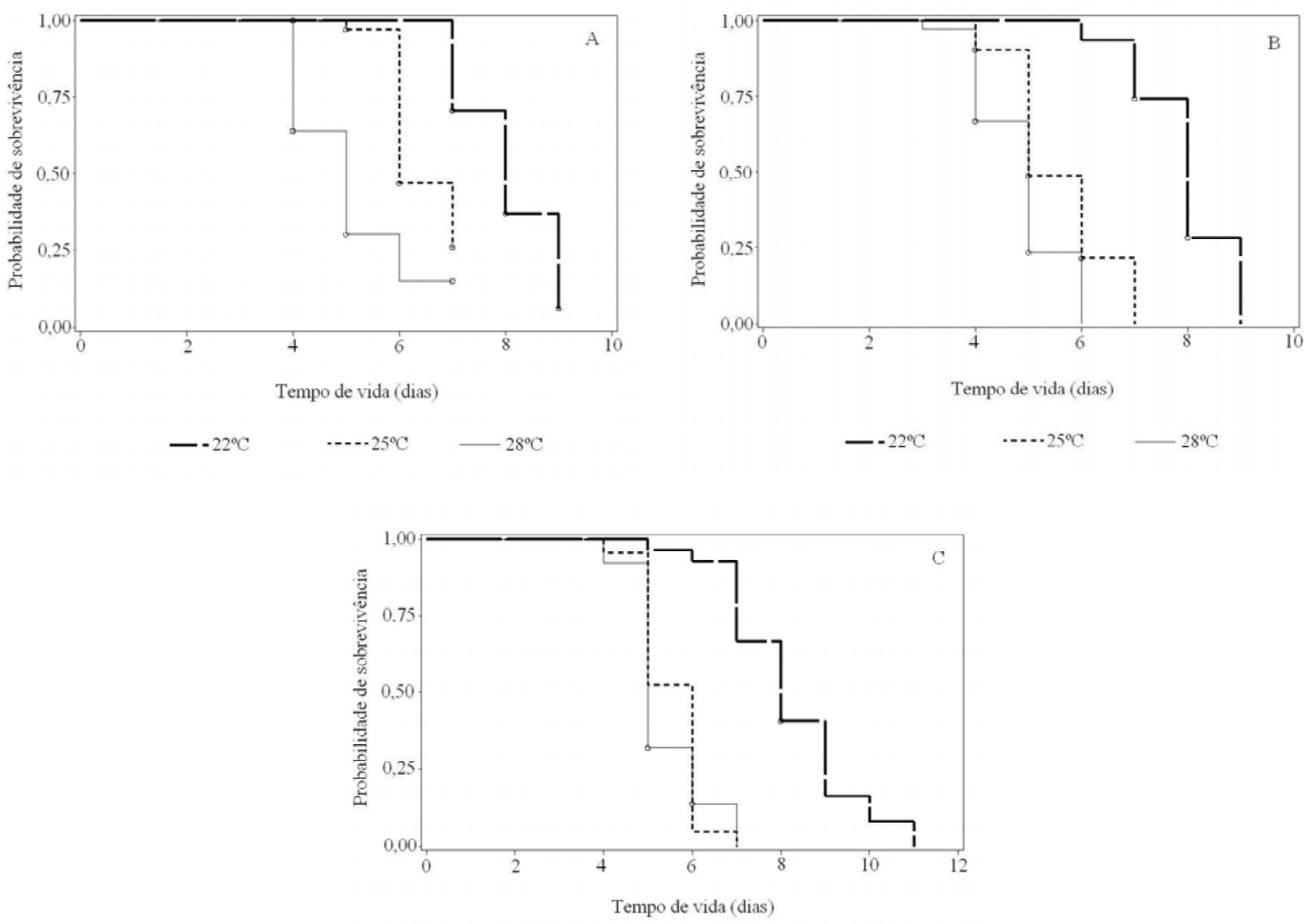

$-22^{\circ} \mathrm{C} \quad \cdots \cdot 25^{\circ} \mathrm{C} \quad-28^{\circ} \mathrm{C}$

Figura 1 - Curvas de sobrevivência para o tempo mediano de vida, em dias do primeiro (A), do segundo (B) e do terceiro ínstares (C) de Ceraeochrysa cubana (Hagen) alimentada com Aphis gossypii Glover, em três temperaturas. UR $70 \pm 10 \%$ e fotofase de 12 horas. 
Na temperatura de $22^{\circ} \mathrm{C}$, as larvas de segundo ínstar tiveram o mesmo tempo mediano de vida das larvas de primeiro ínstar, sob a mesma condição térmica. Observouse que os eventos se iniciaram após seis dias da primeira ecdise e, aos nove dias, todas as larvas sobreviventes passaram para o estádio seguinte. No entanto, a maioria dos eventos ocorreu no tempo mediano de vida de oito dias e, nesse dia, a probabilidade de sobrevivência foi de $28,26 \%$, indicando que $71,74 \%$ das larvas mudaram de ínstar (Tabela 1 e Figura 1B).

$\mathrm{Na}$ temperatura de $25^{\circ} \mathrm{C}$, as larvas no segundo estádio tiveram o maior número de eventos ocorridos no tempo mediano de cinco dias e, nesse período, ainda havia $48,64 \%$ de larvas para sofrerem ecdise, sendo que $51,36 \%$ já estavam no terceiro ínstar (Tabela 1). As mudanças de ínstar ocorreram ao longo de quatro dias, com início aos quatro dias e término aos sete dias da primeira ecdise (Figura 1B).

As larvas de segundo ínstar criadas a $28^{\circ} \mathrm{C}$ apresentaram o tempo mediano de cinco dias, com ocorrência, nesse dia, do maior número de eventos, os quais iniciaram-se aos três dias e terminaram no sexto dia, quando foi possível verificar que todas as larvas sobreviventes mudaram para o terceiro estádio (Tabela 1 e Figura 1B). O total de larvas que passaram para o terceiro ínstar no tempo mediano foi de $76,47 \%$, restando $23,53 \%$ das larvas para sofrerem o processo de ecdise (Figura 1B).

O tempo mediano das larvas de terceiro ínstar mantidas a $22^{\circ} \mathrm{C}$ não variou com relação aos ínstares anteriores, que foi de oito dias, na mesma temperatura, mas, apresentou uma probabilidade de sobrevivência de $40,74 \%$, ou seja, $59,26 \%$ delas mudaram para a fase de prépupa (Tabela 1). Os eventos tiveram início no período de cinco dias e terminaram no tempo de onze dias (Figura 1C).

A $25^{\circ} \mathrm{C}$, as larvas de terceiro ínstar tiveram o mesmo tempo mediano de vida daquelas de primeiro ínstar (seis dias), com probabilidade de sobrevivência de $23,53 \%$, sendo que $76,47 \%$ foi a porcentagem de pré-pupas formadas nesse dia (Tabela 1). Foi no quarto dia que os eventos começaram a ocorrer e terminaram no sétimo dia (Figura 1C).

No último estádio larval, a $28^{\circ} \mathrm{C}$, algumas larvas iniciaram o processo de confecção do casulo com quatro dias, mas a maioria das larvas passou para o estágio de pré-pupa com cinco dias e, aos sete dias, todas as larvas já se encontravam na fase pré-pupal. A probabilidade de sobrevivência no tempo mediano de cinco dias foi de 32\%, verificando-se que, nesse dia, $68 \%$ das larvas mudaram para a fase de pré-pupa (Tabela 1 e Figura 1C).

Ao analisar as curvas de sobrevivência de cada ínstar, verificou-se a influência da temperatura no desenvolvimento das larvas de $C$. cubana alimentadas com ninfas de A. gossypii. Constatou-se uma diminuição no tempo de vida das larvas à medida que ocorreu o aumento da temperatura. $\mathrm{O}$ aumento de $3^{\circ} \mathrm{C}$ permitiu reduções no tempo de duração das larvas nos três ínstares em menor intensidade. No primeiro e terceiro ínstares, verificou-se uma redução de dois dias, quando se aumentou a temperatura de 22 para $25^{\circ} \mathrm{C}$, e no segundo ínstar, houve uma redução de três dias. Quando as larvas encontravamse no primeiro e terceiro ínstares, o aumento da temperatura de 25 para $28^{\circ} \mathrm{C}$ causou uma redução de um dia no tempo mediano de vida dessas larvas e esse aumento não causou diferença no tempo de vida observado para larvas de segundo ínstar.

Essa redução da duração de cada ínstar, em função do aumento da temperatura, também foi evidenciado por Silva (1991) e Venzon (1991) para essa mesma espécie de predador, alimentada com diferentes presas. Venzon (1991) encontrou duração média de $8 ; 5$ e 4 dias para o primeiro ínstar, de 7; 4 e 3 dias para o segundo ínstar e de 10; 5 e 4 dias para o terceiro ínstar, nas temperaturas de $20 ; 25$ e $30^{\circ} \mathrm{C}$, respectivamente. Silva (1991), nas mesmas temperaturas verificou, para o primeiro instar, duração de 7; 4 e 3 dias; de 8; 4 e 3 dias para o segundo ínstar e, para o terceiro ínstar a duração foi de 10; 5 e 5 dias, respectivamente. Esses resultados divergiram dos constatados na presente pesquisa, provavelmente pelo fato de terem sido outras as temperaturas testadas, devendo-se considerar também uma possível influência da alimentação que, dependendo da quantidade e qualidade, pode prolongar ou reduzir o desenvolvimento de um predador, como mencionado por Smith (1921).

López-Arroyo et al. (1999a) verificaram que o desenvolvimento das fases imaturas de C. cubana, Ceraeochrysa cincta (Schneider, 1851) e Ceraeochrysa smithi (Navás, 1914) também diminuiu com a elevação da temperatura, constatando a importância desse fator sobre o desenvolvimento de espécies de crisopídeos.

Fases de pré-pupa e pupa - $\mathrm{O}$ tempo mediano para a fase de pré-pupa foi de sete dias, quando submetidas à temperatura de $22^{\circ} \mathrm{C}$ (Tabela 2). No sétimo dia, atingiu-se uma probabilidade de sobrevivência de $11,54 \%$, podendose constatar que $88,46 \%$ das pré-pupas passaram para a fase seguinte, visto que os eventos se constituíram apenas de mudança de fase (Figura 3A). Os eventos se iniciaram no terceiro dia e terminaram no nono dia. No tempo de quatro e cinco dias, não ocorreu nenhuma mudança (Figura 2A).

$\mathrm{Na}$ temperatura de $25^{\circ} \mathrm{C}$, o tempo mediano de vida foi de cinco dias com probabilidade de sobrevivência de $9,52 \%$, indicando que $90,48 \%$ das pré-pupas passaram para 
a fase seguinte (Tabela 2). As mudanças da fase começaram a ocorrer no quarto dia e terminaram no sexto dia (Figura 2A).

O menor tempo mediano de vida na fase de prépupa foi constatado na temperatura de $28^{\circ} \mathrm{C}$, na qual o maior número de pupas recém-formadas foi observado no tempo mediano de quatro dias. A probabilidade de sobrevivência nesse tempo foi de $28 \%$, indicando que $72 \%$ das pré-pupas mudaram para a fase pupal nesse dia (Tabela 2). Os eventos ocorreram em cinco dias, com início no terceiro, tendo, no quarto dia, a maioria das pré-pupas atingido a fase seguinte e a última delas alcançou a fase de pupa com oito dias de vida (Figura 2A).

Para a fase de pupa na menor temperatura, o tempo mediano observado foi de treze dias, tendo nesse dia, $53,85 \%$ das pupas mudado para a fase adulta (Tabela 2 ). No décimo terceiro dia, observou-se o maior número de pupas em processo de emergência. Os primeiros adultos começaram a emergir no décimo dia, e no décimo quinto dia, não havia mais nenhuma pupa, pois todas elas haviam se transformado em adultos (Figura 2B).

A $25^{\circ} \mathrm{C}$, o tempo mediano de vida foi de nove dias, período em que se concentrou o maior número de eventos. A probabilidade de sobrevivência encontrada nesse dia foi de $23,81 \%$, ou seja, $76,19 \%$ das pupas passaram para a fase adulta (Tabela 2). Os adultos começaram a emergir no sétimo dia e, no décimo dia, não havia mais nenhuma pupa (Figura 3B).

Quando as pupas foram submetidas à temperatura de $28^{\circ} \mathrm{C}$, o maior número de eventos relacionados com a mudança de fase ocorreu no tempo mediano de oito dias, com probabilidade de sobrevivência de $8,73 \%$, sendo essa a porcentagem de pupas que ainda não haviam se transformado em adulto, ao passo que $91,27 \%$ delas transformaram-se em adultos nesse tempo (Tabela 2). Os eventos ocorreram ao longo de quatro dias, com início no sexto dia e término aos nove dias do surgimento da primeira pupa (Figura 2B).

Tabela 2 - Tempo mediano de vida (T) em dias e probabilidade de sobrevivência (S) em \%, das fases de pré-pupa e pupa de Ceraeochrysa cubana (Hagen) alimentada com Aphis gossypii Glover em três temperaturas. UR de $70 \pm 10 \%$ e fotofase de 12 horas.

\begin{tabular}{ccccc}
\hline \multirow{2}{*}{ Fases } & \multicolumn{4}{c}{ Temperaturas $\left({ }^{\circ} \mathrm{C}\right)$} \\
\cline { 2 - 5 } & & 22 & 25 & 28 \\
\hline \multirow{2}{*}{ Pré-pupa } & $\mathrm{T}$ & 7 & 5 & 4 \\
& $\mathrm{~S}$ & 11,54 & 9,52 & 8 \\
\hline \multirow{2}{*}{ Pupa } & $\mathrm{T}$ & 13 & 9 & 8,73 \\
& $\mathrm{~S}$ & 46,15 & 23,81 & 800 \\
\hline
\end{tabular}

$\mathrm{T}=$ tempo mediano em que a maioria das larvas sofreu ecdise. $\mathrm{S}=$ porcentagem de larvas que ainda não sofreram ecdise no tempo $\mathrm{T}$.
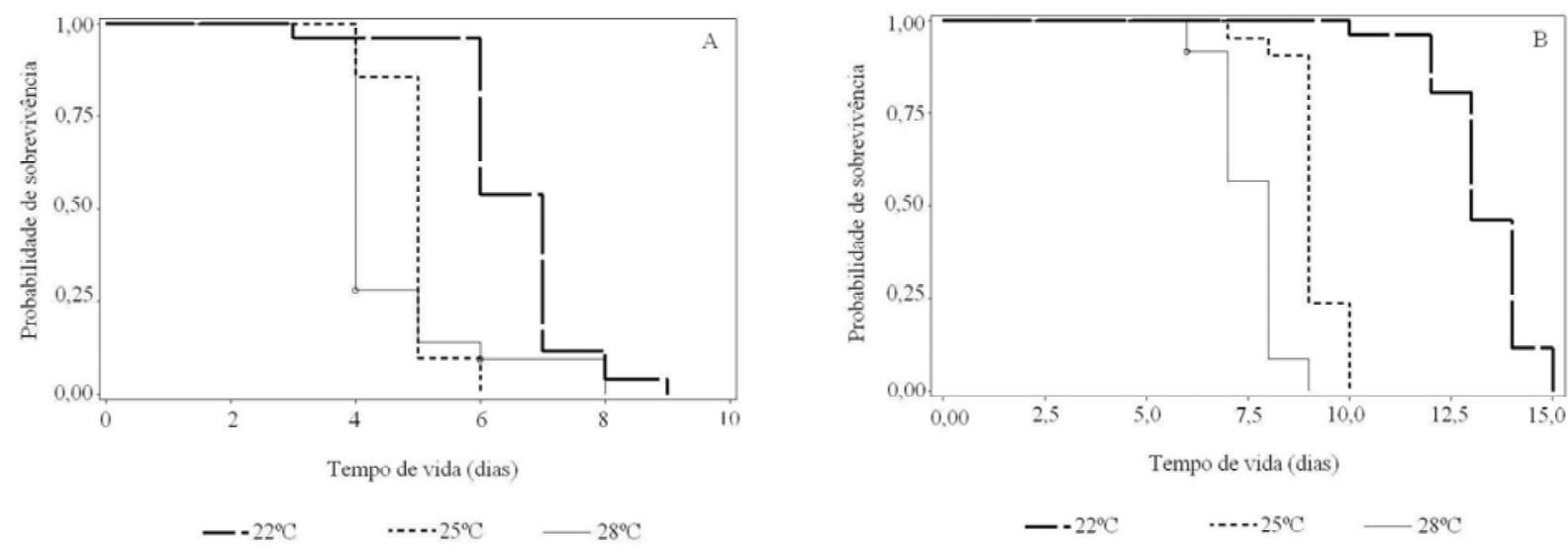

Figura 2 - Curvas de sobrevivência para o tempo mediano de vida (em dias) das fases de pré-pupa (A) e de pupa (B) de Ceraeochrysa cubana (Hagen) alimentada com Aphis gossypii Glover, em três temperaturas. UR $70 \pm 10 \%$ e fotofase de 12 horas. 
Observou-se que as curvas de sobrevivência relacionadas à fase de pré-pupa e pupa diferiram em função das temperaturas estudadas. Com o aumento da temperatura, verificou-se uma redução no tempo de permanência nessas fases. Em todas as temperaturas, a fase de pupa teve maior duração que a fase de pré-pupa.

Venzon (1991) verificou, para a fase pré-pupal de $C$. cubana alimentada com diferentes dietas, duração intermediária a $20^{\circ} \mathrm{C}$, quando comparada àquela significativamente maior, obtida a $25^{\circ} \mathrm{C}$, e aquela menor, verificada a $30^{\circ} \mathrm{C}$, discordando com os resultados do presente trabalho. Para a fase de pupa, a duração decresceu com o aumento da temperatura, variando, em média, de 22 a 8 dias, nas temperaturas de 20 e $30^{\circ} \mathrm{C}$, respectivamente, assemelhando-se aos resultados obtidos na presente pesquisa. Esse mesmo comportamento também foi observado por Silva (1991) para fase de pupa de C. cubana, cujas larvas foram alimentadas com outro tipo de presa, encontrando-se duração média de $31 ; 23 ; 13 ; 10$ e 10 dias nas temperaturas de $18 ; 20 ; 25 ; 30$ e $32^{\circ} \mathrm{C}$, respectivamente.

Viabilidade - A viabilidade da fase de larva de $C$. cubana alimentada com A. gossypii foi afetada pelas temperaturas estudadas. A maior viabilidade encontrada foi na temperatura de $22^{\circ} \mathrm{C}$ e a menor foi a $25^{\circ} \mathrm{C}$. A temperatura de $28^{\circ} \mathrm{C}$ proporcionou a menor viabilidade nas fases de pré-pupa e pupa, e no período de larva a adulto, a maior viabilidade encontrada foi na temperatura de $22^{\circ} \mathrm{C}$ e a menor na temperatura de $25^{\circ} \mathrm{C}$ (Tabela 3 ).

Silva (1991), trabalhando com a mesma espécie de predador nas temperaturas de $20 ; 25$ e $30^{\circ} \mathrm{C}$, encontrou viabilidades de 90 a $100 \%$ para a fase larval, de 60 a $80 \%$ para a fase pupal e de 50 a $70 \%$ para o ciclo total (ovo a adulto). As diferenças encontradas nessas pesquisas possivelmente ocorreram em função das variações nas condições experimentais, bem como da espécie de presa fornecida. Isso foi comprovado por Venzon (1991) que obteve resultados próximos aos de Silva (1991), quando estudou o desenvolvimento de larvas de $C$. cubana alimentada com diferentes presas nas temperaturas de 20; 25 e $30^{\circ} \mathrm{C}$.

Na temperatura de $24 \pm 1^{\circ} \mathrm{C}, C$. cubana alimentada com o pulgão Myzus persicae (Sulzer, 1776) (Hemiptera: Aphididae) apresentou viabilidades de 100; 85,4; 74,6 e 94,1\% para as fases de larva, pré-pupa, pupa e para o período de larva a adulto, respectivamente, mostrando que tanto a temperatura como o tipo de presa foram adequados ao desenvolvimento desse predador (LÓPEZ-ARROYO et al., 1999b).

López-Arroyo et al. (1999a), observaram que larvas de $C$. cubana mantidas na faixa de 18,3 a $29,1^{\circ} \mathrm{C}$ com variação de $3^{\circ} \mathrm{C}$ entre as temperaturas, não apresentaram diferença significativa para viabilidade das fases imaturas. Esses resultados divergem dos obtidos no presente trabalho, no qual foi possível verificar que a temperatura de $22^{\circ} \mathrm{C}$ proporcionou a maior viabilidade em todas fases avaliadas (Tabela 3).

Capacidade predatória de Ceraeochrysa cubana em três temperaturas - Consumo médio diário - Verificouse que não houve diferença significativa no consumo médio diário das larvas de primeiro ínstar do predador em função da temperatura. As temperaturas de 22 e $25^{\circ} \mathrm{C}$ também não afetaram de modo significativo o número médio diário de pulgões consumidos por larvas de segundo e terceiro ínstares, porém, as larvas, nesses estádios, passaram a consumir mais ninfas de A. gossypii quando submetidas à temperatura de $28^{\circ} \mathrm{C}$ (Tabela 4). Esse aumento na capacidade predatória diária de larvas de segundo e terceiro ínstares, sob temperaturas mais elevadas, possivelmente, foi devido à maior atividade metabólica, característica da relação entre a maior atividade de organismos pecilotérmicos e a temperatura.

Tabela 3 - Viabilidade (\%) das fases de larva, pré-pupa, pupa e do período de larva a adulto de Ceraeochrysa cubana (Hagen) alimentada com Aphis gossypii Glover, em três temperaturas. UR de 70 $\pm 10 \%$ e fotofase de 12 horas.

\begin{tabular}{ccccc}
\hline $\begin{array}{c}\text { Temperatura } \\
\left({ }^{\circ} \mathrm{C}\right)\end{array}$ & Fase de larva & Pré-pupa & Pupa & $\begin{array}{c}\text { Período de larva a } \\
\text { adulto }\end{array}$ \\
\hline 22 & $67,5 \mathrm{a}$ & $100,0 \mathrm{a}$ & $100,0 \mathrm{a}$ & $65,0 \mathrm{a}$ \\
& $(27)^{*}$ & $(26)^{*}$ & $(26)^{*}$ & $(26)^{*}$ \\
25 & $52,5 \mathrm{c}$ & $100,0 \mathrm{a}$ & $100,0 \mathrm{a}$ & $52,5 \mathrm{c}$ \\
& $(21)^{*}$ & $(21)^{*}$ & $(21)^{*}$ & $(21)^{*}$ \\
28 & $62,5 \mathrm{~b}$ & $96,0 \mathrm{~b}$ & $95,83 \mathrm{~b}$ & $57,5 \mathrm{~b}$ \\
\end{tabular}

*Valores entre parênteses referem-se ao número de indivíduos observados.

Porcentagens seguidas das mesmas letras nas colunas não diferem entre si, pelo teste de Tukey a 5\%. 
Os resultados obtidos por Figueira et al. (2002) mostraram o aumento progressivo na capacidade predatória diária de larvas de Chrysoperla externa (Hagen, 1861) (Neuroptera: Chrysopidae), nos três ínstares, alimentadas com ovos de Alabama argillacea (Hübner, 1818) (Lepidoptera: Noctuidae), com a elevação da temperatura, contrastando com o consumo diário de ninfas de A. gossypii por larvas de $C$. cubana nas temperaturas de 22 e $25^{\circ} \mathrm{C}$ (Tabela 4).

Nas temperaturas estudadas o número de pulgões predados diariamente por larvas de $C$. cubana aumentou do primeiro para o terceiro ínstar, como verificado por Figueira et al. (2002) e Fonseca et al. (2001), para C. externa alimentada com outros tipos de presas e em outras condições térmicas. Isso se deve, principalmente, ao fato de as larvas de terceiro ínstar apresentarem maior tamanho e, assim, necessitarem de maior quantidade de alimento para completar seu desenvolvimento.

Consumo médio total - $\mathrm{O}$ consumo médio total do primeiro e segundo ínstares não diferiu significativamente em função das temperaturas estudadas. Porém, para o terceiro instar, essa diferença foi evidente, sendo o consumo total maior na temperatura de $22^{\circ} \mathrm{C}$, reduzindo a $25^{\circ} \mathrm{C}$ e apresentando novo aumento a $28^{\circ} \mathrm{C}$ (Tabela 5).

O número total de $A$. gossypii predado, durante a fase larval diminuiu em conseqüência do aumento da temperatura de 22 para $25^{\circ} \mathrm{C}$ (Tabela 5), devido certamente, à redução dessa fase sob temperaturas mais elevadas, expondo as larvas a um período mais curto de alimentação. Observação semelhante também foi feita por Figueira et al. (2002), uma vez que o consumo de ovos de A. argillacea por larvas de $C$. externa reduziu de $344,2 \pm 17,1$ para $322,5 \pm 47,4$ nas temperaturas de 21 e $27^{\circ} \mathrm{C}$, respectivamente. $\mathrm{O}$ teste de médias não detectou diferença significativa no número de ninfas de $A$. gossypii consumidas na fase larval de $C$. cubana nas temperaturas de 25 e $28^{\circ} \mathrm{C}$.

Fonseca et al. (2001) apresentaram resultados discrepantes, quando verificaram que o aumento da temperatura resultou num aumento progressivo do número total de ninfas de Schizaphis graminum (Rondani, 1852) (Hemiptera: Aphididae) consumidas por larvas de $C$. externa, nos três ínstares e na fase de larva, provavelmente devido a um aumento progressivo no metabolismo das larvas, sob condições térmicas mais elevadas.

Tabela 4 - Número médio diário ( \pm EP) de ninfas de Aphis gossypii Glover consumidas por larvas de Ceraeochrysa cubana (Hagen), nos três ínstares, em três temperaturas. UR de $70 \pm 10 \%$ e fotofase de 12 horas.

\begin{tabular}{crrrr}
\hline \multirow{2}{*}{ Ínstares } & \multicolumn{3}{c}{ Temperaturas $\left({ }^{\circ} \mathrm{C}\right)$} & \multirow{2}{*}{ Valores de P } \\
\cline { 2 - 4 } & \multicolumn{1}{c}{22} & \multicolumn{1}{c}{25} & \multicolumn{1}{c}{28} & 0,1725 \\
$1^{\mathrm{o}}$ & $2,39 \pm 0,08 \mathrm{a}$ & $2,94 \pm 0,12 \mathrm{a}$ & $4,10 \pm 0,12 \mathrm{a}$ & $<0,0001$ \\
$2^{\underline{\mathrm{o}}}$ & $8,56 \pm 0,28 \mathrm{~b}$ & $10,78 \pm 0,34 \mathrm{~b}$ & $12,76 \pm 0,36 \mathrm{a}$ & $<0,0001$ \\
$3^{\mathrm{o}}$ & $62,71 \pm 1,55 \mathrm{~b}$ & $67,19 \pm 1,73 \mathrm{~b}$ & $78,29 \pm 1,11 \mathrm{a}$ & \\
\hline $\mathrm{CV}(16,64 \%)$ & & &
\end{tabular}

Médias seguidas pela mesma letra na linha não diferem entre si, pelo teste de Tukey a 5\%.

$\mathrm{CV}=$ coeficiente de variação. $\mathrm{EP}$ = erro padrão. $\mathrm{P}=$ probabilidade de significância.

Tabela 5 - Número médio total ( \pm EP) de ninfas de Aphis gossypii Glover consumidas por larvas de Ceraeochrysa cubana (Hagen) nos três ínstares e na fase larval, em três temperaturas. UR de $70 \pm 10 \%$ e fotofase de 12 horas.

\begin{tabular}{|c|c|c|c|c|}
\hline \multirow{2}{*}{ Ínstares } & \multicolumn{3}{|c|}{ Temperaturas $\left({ }^{\circ} \mathrm{C}\right)$} & \multirow{2}{*}{ Valores de $\mathrm{P}$} \\
\hline & 22 & 25 & 28 & \\
\hline $1^{\mathrm{o}}$ & $18,26 \pm 0,68 \mathrm{a}$ & $18,18 \pm 0,89 \mathrm{a}$ & $18,86 \pm 0,88 \mathrm{a}$ & 0,9965 \\
\hline $2^{\underline{o}}$ & $66,58 \pm 2,53 \mathrm{a}$ & $55,61 \pm 2,27 \mathrm{a}$ & $57,79 \pm 2,38 \mathrm{a}$ & 0,4814 \\
\hline $3^{\mathrm{o}}$ & $511,11 \pm 17,48 \mathrm{a}$ & $367,48 \pm 12,75 \mathrm{c}$ & $409,84 \pm 11,27 \mathrm{~b}$ & $<0,0001$ \\
\hline Fase larval & $596,26 \pm 19,99 \mathrm{a}$ & $441,33 \pm 12,77 \mathrm{~b}$ & $488,00 \pm 12,52 \mathrm{~b}$ & $<0,0001$ \\
\hline
\end{tabular}

CV $(26,22 \%)$ ínstares. CV (14,99\%) fase larval

Médias seguidas pela mesma letra na linha não diferem entre si pelo teste de Tukey a 5\%.

$\mathrm{CV}=$ coeficiente de variação. $\mathrm{EP}=$ erro padrão. $\mathrm{P}=$ probabilidade de significância. 
O consumo total de pulgões por larvas de terceiro ínstar de C. cubana representou cerca de $80 \%$ do consumo total durante o período larval nas três temperaturas. Isso, porque larvas de terceiro ínstar são maiores que as de primeiro e de segundo ínstares e, necessitam de maior quantidade de alimento para suprir sua necessidade nutricional. Resultados semelhantes foram obtidos por Fonseca et al. (2001) que avaliaram a capacidade predatória de $C$. externa alimentada com o pulgão $S$. graminum em seis temperaturas, e por Figueira et al. (2002) que estudaram a influência de diferentes temperaturas no consumo de ovos de A. argillacea por larvas de C. externa.

\section{CONCLUSÕES}

A temperatura afetou o tempo mediano de vida e a viabilidade de $C$. cubana alimentada com A. gossypii.

O consumo de pulgões por $C$. cubana foi influenciado pela temperatura e pelo estádio de desenvolvimento das larvas.

\section{REFERÊNCIAS BIBLIOGRÁFICAS}

FIGUEIRA, L. K.; CARVALHO, C. F.; SOUZA, B. Influência da temperatura sobre alguns aspectos biológicos de Chrysoperla externa (Hagen, 1861) (Neuroptera: Chrysopidae) alimentada com ovos de Alabama Argillacea (Hübner, 1818) (Lepidoptera: Noctuidae). Ciência e Agrotecnologia, Lavras, v. 26, p. 1439-1450, dez. 2002. Edição especial.

FONSECA, A. R.; CARVALHO, C. F.; SOUZA, B. Capacidade predatória e aspectos biológicos das fases imaturas de Chrysoperla externa (Hagen, 1861) (Neuroptera: Chrysopidae) alimentada com Schizaphis graminum (Rondani, 1852) (Hemiptera: Aphididae) em diferentes temperaturas. Ciência e Agrotecnologia, Lavras, v. 25, n. 2, p. 251-263, abr./jun. 2001

KARAHROUDI, Z. R.; HATAMI, B. Comparison of two methods of releasing Chrysoperla carnea (Steph.) eggs against Aphis gossypii Glov. under greenhouse conditions. Journal of Science and Technology of Agriculture and Natural Resources, Adelaide, v. 7, n. 2, p. 215-225, 2003.

LÓPEZ-ARROYO, J. I.; TAUBER, C. A.; TAUBER, M. J. Comparative life histories of the predators Ceraeochrysa cincta, C. cubana, and C. smith (Neuroptera: Chrysopidae). Annals of the Entomological Society of América, Lanham, v. 92 , n. 2, p. 208-217, Mar. 1999a.

LÓPEZ-ARROYO, J. I.; TAUBER, C. A.; TAUBER, M. J. Effects of prey survival, development, and reproduction of trash-carryng chrysopids (Neuroptera: Ceraeochrysa). Environmental Entomology, Lanham, v. 28, n. 6, p. 11831188, Dec. 1999b.

NÚÑEZ, Z. E. Ciclo biológico y crianza de Chrysoperla externa y Ceraeochrysa cincta (Neuroptera: Chrysopidae). Revista Peruana de Entomologia, Lima, v. 31, p. 76-82, 1988.

PESSOA, L. G. A.; LEITE, M. V. de; FREITAS, S.; GARBIN, G. C. Efeito da variação da temperatura sobre o desenvolvimento embrionário e pós-embrionário de Ceraeochrysa paraguaria (Navás) (Neuroptera: Chrysopidae). Arquivos do Instituto Biológico, São Paulo, v. 71, n. 4, p. 473-476, out./dez. 2004.

SILVA, R. L. X. Aspectos biológicos e determinação das exigências térmicas de Ceraeochrysa cubana (Hagen, 1861) (Neuroptera: Chrysopidae) em laboratório. 1991. 160 f. Dissertação (Mestrado em Agronomia/Entomologia) - Universidade Federal de Lavras, Lavras, 1991.

SMITH, R. C. A study of the biology of the Chrysopidae. Annals of the Entomological Society of America, Lanham, v. 14, n. 1, p. 27-35, 1921.

STEEZL, M.; DEVETAK, D. Neuroptera in agricultural ecosystems. Agriculture Ecosystems and Environment, Amsterdam, v. 74, n. 1/3, p. 305-321, 1999.

TAUBER, C. A.; TAUBER, M. J.; NECHOLS, J. R. Thermal requirements for development in Chrysopa oculata: a geographically stable trait. Ecology, Washington, v. 68, n. 5, p. 1479-1487, Oct. 1987.

VENZON, M. Biologia de Ceraeochrysa cubana (Hagen, 1861) (Neuroptera, Chrysopidae) em diferentes dietas e temperaturas. 1991. 122 f. Dissertação (Mestrado em Agronomia/Entomologia) - Universidade Federal de Lavras, Lavras, 1991. 